\title{
Anti-Inflammatory Effect of 3-Methylcarbazoles on RAW 264.7 Cells Stimulated with LPS, Polyinosinic-Polycytidylic Acid and Pam3CSK
}

\author{
Thongchai Taechowisan $^{1 *}$, Srisakul Chanaphat ${ }^{1}$, Wanwikar Ruensamran ${ }^{2}$, Waya S. Phutdhawong ${ }^{2}$ \\ ${ }^{1}$ Department of Microbiology, Faculty of Science, Silpakorn University, Bangkok, Thailand \\ ${ }^{2}$ Department of Chemistry, Faculty of Science, Silpakorn University, Bangkok, Thailand \\ Email: *thongch@su.ac.th
}

Received February 7, 2012; revised February 20, 2012; accepted March 20, 2012

\begin{abstract}
In the present study, 3-methylcarbazole and 1-methoxy-3-methylcarbazole were isolated from the culture of Streptomyces sp. LJK109, endophyte of Alpinia galanga Swartz. 3-methylcarbazole, a carbazole derivative, has been found to be highly potent as anti-inflammatory agent. The immunomodulatory activity of these agents in toll like receptor (TLR)activated RAW 264.7 macrophages induced by lipopolysaccharide (LPS), Poly(I:C), and pam3CSK was investigated by assessing nitric oxide (NO) and pro-inflammatory cytokines. The 3-methylcarbazoles dose-dependently suppressed the release of NO, PGE 2 , TNF- $\alpha$, IL-1 $\beta$, IL-6 and IL-10 in LPS- and pam3CSK-activated macrophages but not in Poly(I:C)activated macrophages. Our results suggest that 3-methylcarbazoles can be further developed as a promising anti-inflammatory remedy.
\end{abstract}

Keywords: 3-Methylcarbazoles; Anti-Inflammatory Activity; RAW 264.7 Cells; Streptomyces sp.

\section{Introduction}

Some of actinomycete could be isolated from the tissue of healthy plants which was called endophytic actionmycetes $[1,2]$. Several reports refer to endophytic actinomycetes produced bioactive compounds [3-7]. Recently, we isolated an endophytic actinomycete from the root tissues of Alpinia galanga Swartz (Zingiberaceae) which has antifungal activity and it was identified as Streptomyces sp. LJK109. Extraction of the culture medium of this strain afforded 3-methylcarbazoles as a major active ingredient, which displayed very strong antifungal activity. Because of 3-methylcarbazoles were a derivative of 6-chloro-a-methylcarbazole-2-acetic acid (carprofen, Imadyl), which was used as a nonsteroid anti-inflammatory agent $[8,9]$. Thus, the anti-inflammatory effects of 3methylcarbazoles on macrophages and its inhibitory mechanisms remain to be elucidated. We investigated the immunomodulatory activity of 3-methylcarbazoles on activated macrophages induced by toll like receptor (TLR) ligands such as LPS (a TLR4 ligand), polyinosinic-polycytidylic acid (Poly(I:C)) (a TLR3 ligand), and $N$-palmitoyl-S-[2,3-bis(palmitoloxy)-(2RS)-propyl]-Cys-Ser-Lys 4 (pam3CSK) (a TLR2 ligand); in addition to nitric oxide (NO), prostaglandin $\mathrm{E}_{2}\left(\mathrm{PGE}_{2}\right)$, tumor necrosis factor

\footnotetext{
${ }^{*}$ Corresponding author.
}

(TNF)- $\alpha$, interleukin (IL)-1 $\beta$, IL-6 and IL-10 assays were utilized.

\section{Materials and Methods}

\subsection{Organisms and Compounds}

Streptomyces sp. LJK109 was isolated from the root tissues of Alpinia galanga by the surface sterilization technique [10]. Identification of the isolate to genus level was based on morphological, cultural, physiological, and biochemical characterizatics and also $16 \mathrm{~S}$ rDNA sequencing as described by Taechowisan and Lumyong [11]. Solid medium for sporulation and bioactive compounds production was International Streptomyces Project medium 4 (ISP-4) and ISP-2, respectively. The 10-day-old cultures were extracted three times with ethyl acetate. This organic solvent was pooled and then taken to dryness under flash evaporation to give a dark brown solid ( $340.5 \mathrm{mg}$ ). The solid was separated by column chromatography using silica gel 60 (Merck, $0.040-0.063 \mathrm{~mm}$ ) and $\mathrm{CH}_{2} \mathrm{Cl}_{2} / \mathrm{MeOH}(22: 3)$ as the eluent to give 3-methylcarbazole (1) as a colorless prisms (102.6 mg); m.p. $206^{\circ} \mathrm{C}-207^{\circ} \mathrm{C}$ (from acetone); have the molecular formulae $\mathrm{C}_{13} \mathrm{H}_{11} \mathrm{~N}(\mathrm{M}+, \mathrm{m} / \mathrm{z} 181.233)$ and 1-methoxy-3methylcarbazole (2) as a brown needles $(85.4 \mathrm{mg})$; m.p. $188^{\circ} \mathrm{C}-190^{\circ} \mathrm{C}$ (from benzene); have the molecular for- 
mulae $\mathrm{C}_{14} \mathrm{H}_{13} \mathrm{NO}(\mathrm{M}+, m / z 211.259)$. Their ${ }^{1} \mathrm{H}$ - and ${ }^{13} \mathrm{C}-$ NMR spectral data were identical with those of 3-methylcarbazole and 1-methoxy-3-methylcarbazole previously reported [12-14].

\subsection{Structure Elucidation of the Compounds}

The structures of the active compounds (Figure 1) have been identified using NMR and mass spectral data. The melting point of the compounds was determined on a Buchi-540 melting point apparatus. Optical rotation were measured on a Perkin-Elmer 241 polarimeter, IR spectra on a Perkin-Elmer 1 spectrometer, $1 \mathrm{H}$ and 13C NMR spectra on a Bruker DRX 500 spectrometer, and EI-MS and FAB-MS, respectively, on a Hewlett-Packard 5989 B and a Finnigan/Thermo Quest Mat 95 XL mass spectrometer.

\subsection{Cell Culture and Sample Treatment}

RAW 264.7 murine macrophage cell line was obtained from the Korea Cell Line Bank (Seoul, Korea). These cells were grown at $37^{\circ} \mathrm{C}$ in DMEM medium supplement with $10 \%$ FBS, penicillin (100 units $/ \mathrm{ml}$ ), and streptomycin sulfate $(100 \mu \mathrm{g} / \mathrm{ml})$ in a humidified atmosphere of $5 \%$ $\mathrm{CO}_{2}$. For each experiment, cells were detached with a cell scraper. Experiments were performed at a cell density of $2 \times 10^{6}$ cells $/ \mathrm{ml}$; at this density, more than $99 \%$ of cells were viable according to Trypan blue staining. The stock solution $(100 \mathrm{mg} / \mathrm{ml})$ of 3-methylcarbazoles was dissolved in $100 \%$ DMSO. Non-cytotoxic concentrations $(0-20 \mu \mathrm{g} / \mathrm{ml})$ of 3-methylcarbazoles were prepared by dilution with DMEM medium. After RAW 264.7 cells were incubated for $18 \mathrm{~h}$, cells were pretreated with 3 -methylcarbazoles $(0-20 \mu \mathrm{g} / \mathrm{ml})$ for $30 \mathrm{~min}$. Next, cells were stimulated with LPS $(1 \mu \mathrm{g} / \mathrm{ml})$, Poly(I:C) $(1 \mu \mathrm{g} / \mathrm{ml})$, and pam3CSK $(10 \mu \mathrm{g} / \mathrm{ml})$, and incubated for $24 \mathrm{~h}$.

\subsection{Nitrite Assay}

Nitrite accumulation, an indicator of NO synthesis, was measure in the culture medium by Griess reaction, as described previously [7].

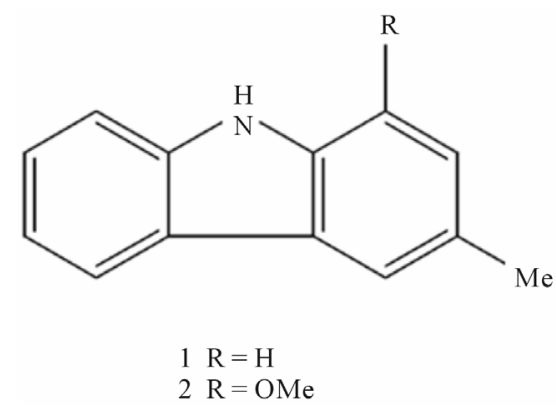

Figure 1. Chemical structures of 3-methylcarbazole (1), and 1-methoxy-3-methylcarbazole (2).

\section{5. $\mathrm{PGE}_{2}, \mathrm{TNF}-\alpha, \mathrm{IL-1} \beta$, IL-6 and IL-10 Assay}

The inhibitory effect of methylcarbazoles on $\mathrm{PGE}_{2}$, TNF$\alpha$, IL- $1 \beta$, IL- 6 and IL-10 production was deter- mined by analyzing $\mathrm{PGE}_{2}, \mathrm{TNF}-\alpha$, IL- $1 \beta$, IL-6 and IL-10 levels with enzyme immunoassay (EIA) kits (Stressgen, USA) according to the manufacturer's instructions.

\subsection{MTT Assay}

Cell proliferation was measured by 3-(4,5-dimethylthiazol-2-yl)-2,5-diphenyl tetrazolium bromide (MTT) assay as described previously [7].

\section{Results and Discussion}

Since the first report of a carbazole alkaloid, murrayanine, from the stem bark of Murraya koenigii [15], a number of carbazole alkaloids have been isolated from this plant [16-20] and other plants [13,21]. Although there are many carbazole alkaloid derivatives that have special ability to scavenge reactive oxygen species-free radicals, such as hydroxyl radicals, superoxide radicals, or hypochlorous acid, and to influence processes involving free-radical injury [22,23], they have also been found to inhibit lipid peroxidation and to possess vasorelaxant [24-26] and anti-inflammatory/antioxidant activity [20]. Moreover they have been reported for their other pharmacological activities such as anticancer [27], antidiarrhoeal [28], antidiabetic [29], antiasthmatic [30], antiplasmodial [31], antibacterial, antifungal and anthelmintic activities [32].

Previous reports indicated that 3-methylcarbazole was produced by numerous species of plants including Murraya euchrestifolia [13], Murraya koenigii [19], Clausena dunniana [33], Micromelum hirsutum [34]. This compound has many biological activities for example: cytotoxicity against both mouse melanoma B16 and adriamycin-resistant P388 mouse leukemia cell lines [19], and growth inhibitory activity on human fibrosarcoma HT1080 cells [33].

In our study, 3-methylcarbazoles was obtained from culture of an endophytic Streptomyces sp. LJK109, isolated from the root tissues of Alpinia galanga. It was the major anti-inflammatory component, so we selected 3methylcarbazoles with a potent NO inhibitory action from the crude extract.

It is well-known that macrophages play a crucial role in both nonspecific and acquired immune responses. We investigated the anti-inflammatory potency of 3-methylcarbazoles using TLR-activated macrophages. As depicted in Figure 2, 3-methylcarbazoles suppressed macrophage production of the inflammatory mediators $\mathrm{NO}$, PGE $_{2}$, TNF- $\alpha$, IL- $1 \beta$, IL- 6 and IL-10 in a dose-dependent manner. The 3-methylcarbazoles mediated suppression regard to the TLR ligand used, the LPS (a TLR4 ligand) 


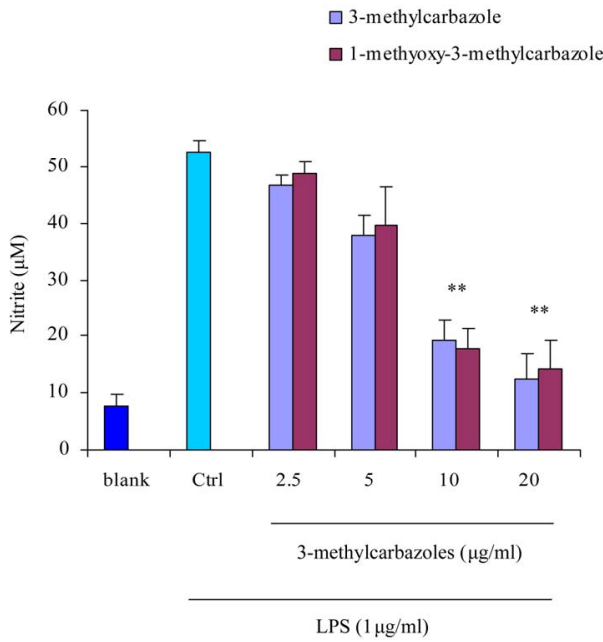

(a)

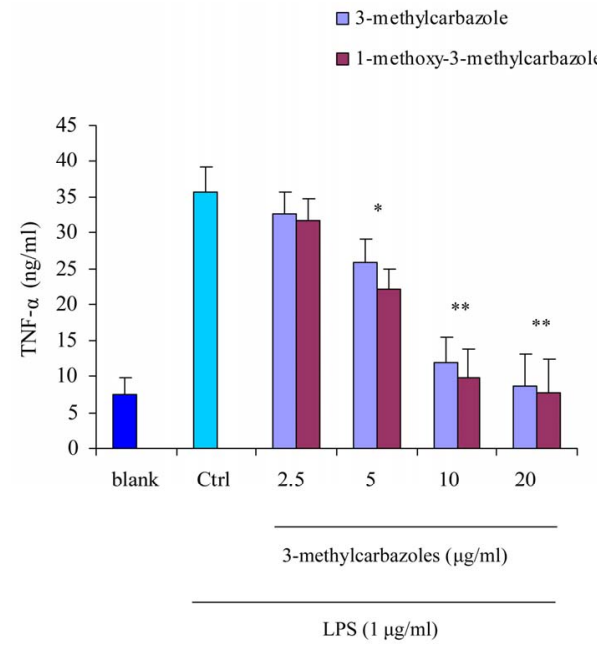

(c)

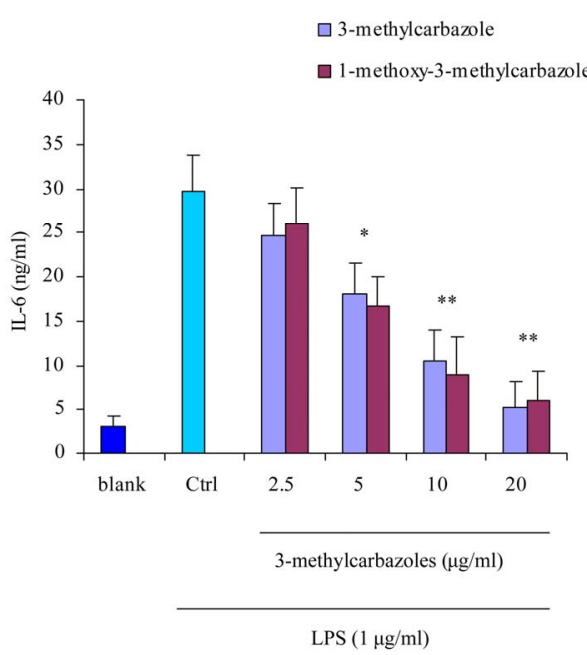

(e)

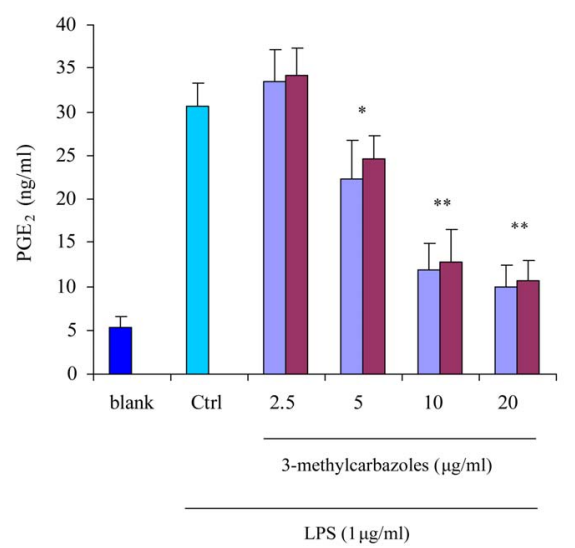

(b)

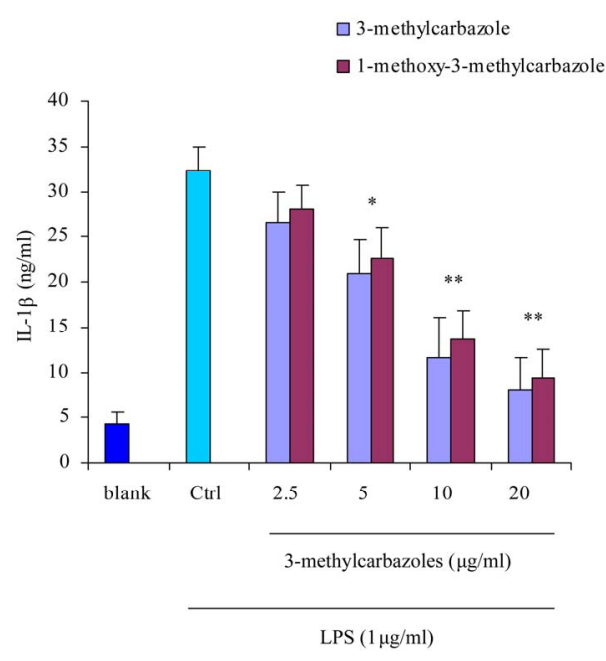

(d)

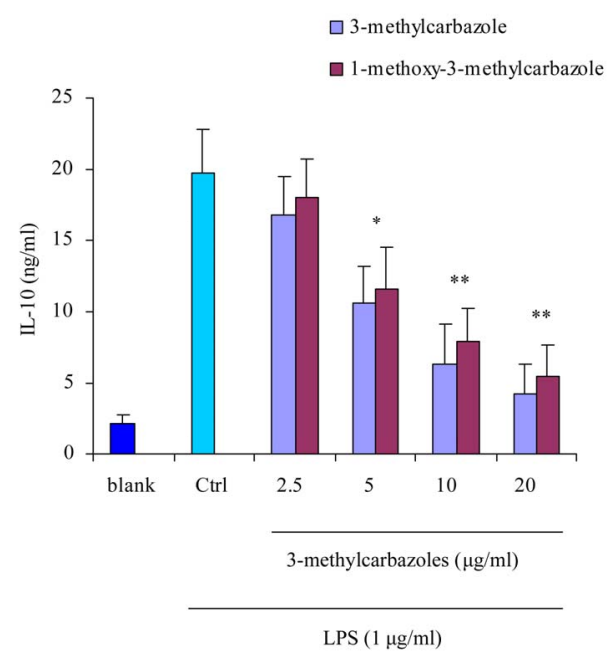

(f)

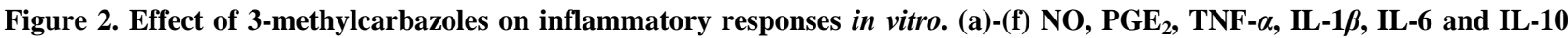
levels in culture supernatants prepared from LPS-activated RAW264.7 cells pretreated with 3-methylcarbazoles, were determined by Griess reagent and EIA. ${ }^{*} p<0.05$ and ${ }^{* *} p<0.01$ compared to the control group. 
and pam3CSK (a TLR2 ligand) had more potential effect than poly(I:C) (a TLR3 ligand) (Figure 3). The reasons may be, TLR3 localized to intracellular vesicles, its activation required to the cell membrance and lipidraft-mediated endocytosis [35] where as TLR4 and TLR2 were located on the cell surface [36]. No cytotoxic activity of 3 -methylcarbazoles was observed under the same conditions (Figure 4), indicating that the immunopharmacological effect of 3-methylcarbazoles was not related to cy-

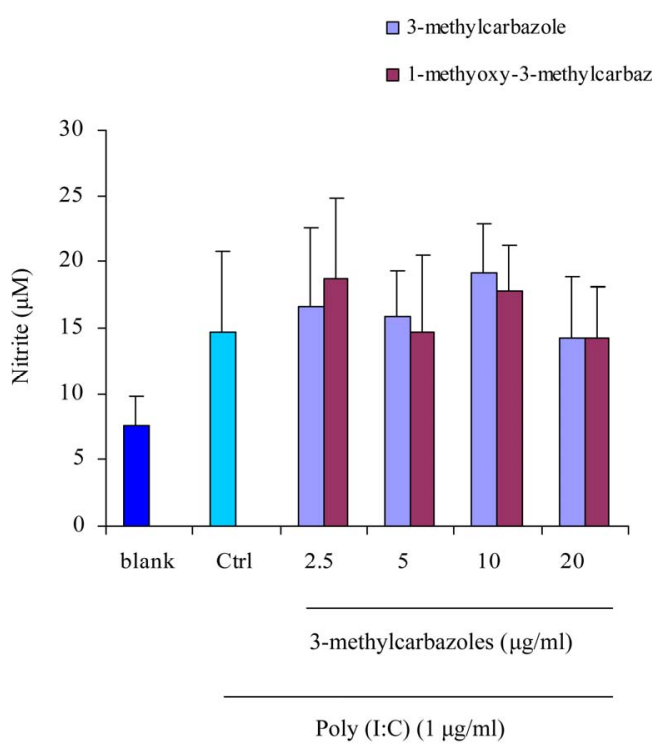

(a)

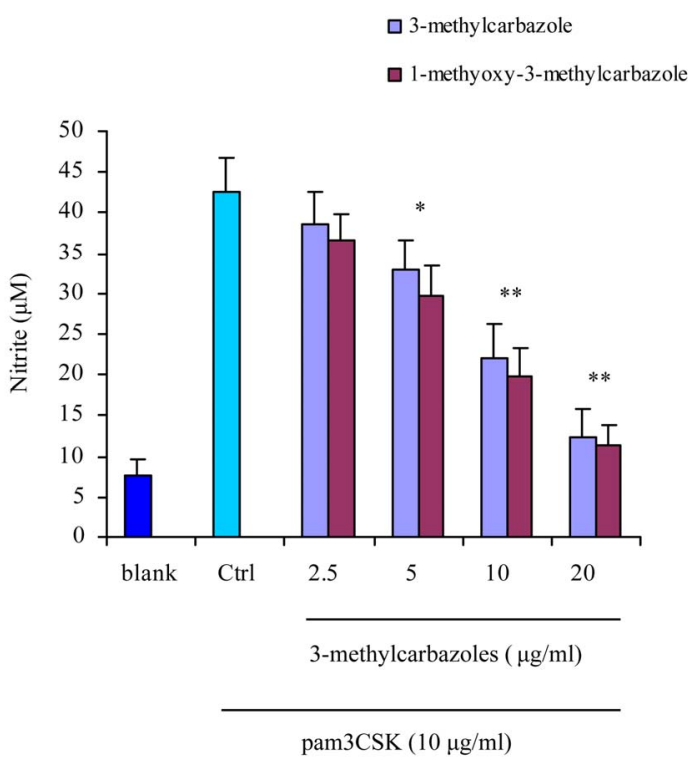

(b)

Figure 3. NO production in culture supernatants prepared from Poly(I:C)-, and pam3CSK-activated RAW264.7 cells pretreated with 3-methylcarbazoles was determined by Griess reagent. ${ }^{*} p<0.05$ and ${ }^{* *} p<0.01$ compared to the control group.

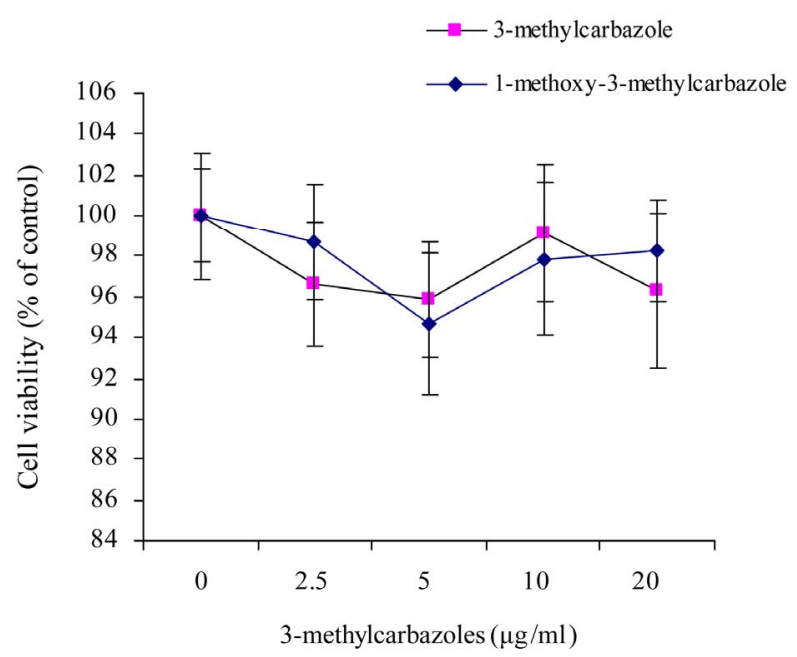

Figure 4. The viability of RAW264.7 cells pretreated with 3methylcarbazoles was determined by MTT assay.

totoxicity. As found with other carbazoles such as 9-(2chlorobenyl)-9H-carbazole-3-carbaldehyde suppressed the NO production in LPS/interferon- $\gamma$-stimulated murine microglial cells [37] and LPS-stimulated murine RAW264.7 cells [38]. These results imply that the inhibitory activity of 3-methylcarbazoles is derived from its ability to block TLR-mediated inflammatory responses. Further investigations are therefore necessary to understand the molecular mechanisms at a transcriptional level and transcription factors that regulate inflammatory gene expression.

In conclusion, we found that 3-methylcarbazoles isolated from Streptomyces sp. LJK109 was able to suppress NO, PGE 2 , TNF- $\alpha$, IL- $1 \beta$, IL-6 and IL-10 production in LPS-, and pam3CSK-treated RAW264.7 macrophages. Verification of therapeutic efficacy of 3-methylcarbazoles as a potent anti-inflammatory remedy will be further studied.

\section{Acknowledgements}

This work was supported by Thailand Research Fund (Research grant No. RMU5480005) and Faculty of Science, Silpakorn University, Thailand.

\section{REFERENCES}

[1] P. Sardi, M. Saracchi, S. Ouaroni, B. Petrolini, G. E. Borgonovoli and S. Merli, "Isolation of Endophytic Streptomyces from Surface-Sterilized Roots," Applied and Environmental Microbiology, Vol. 58, No. 8, 1992, pp. 26912693.

[2] M. Shimizu, Y. Nakagawa, Y. Sato, T. Furumai, Y. Igarashi, H. Onaka, R. Yoshida and H. Kunoh, "Studies on Endophytic Actinomycetes (I) Streptomyces sp. Isolated from Rhododendron and Its Antifungal Activity," Journal of General Plant Pathology, Vol. 366, No. 1, 2000, pp. 360-366. doi:10.1007/PL00012978 
[3] U. F. Castillo, J. K. Harper, G. A. Strobel, J. Sears, K. Alesi, E. J. Ford, J. Lin, M. Hunter, M. Maranta, H. Ge, D. Yaver, J. B. Jenson, H. Porter, R. Robison, D. Millar, W. M. Hess, M. A. Condron and D. B. Teplow, "Kakadumycins, Novel Antibiotics from Streptomyces NRRL 30566, an Endophyte of Grevillea pteridifolia," FEMS Microbiology Letters, Vol. 224, No. 2, 2003, pp. 183-190. doi:10.1016/S0378-1097(03)00426-9

[4] U. F. Castillo, G. A. Strobel, E. J. Ford, W. M. Hess, H. Porter, J. B. Jenson, H. Albert, R. Robison, M. A. Condron, D. B. Teplow, D. Stevens and D. Yever, "Munumbicins, Wide-Spectrum Antibiotics Produced by Streptomyces NRRL 30562, Endophytic on Kennedia nigriscans," Microbiology, Vol. 148, No. 9, 2002, pp. 2675-2685.

[5] D. Ezra, U. F. Castillo, G. A. Strobel, W. M. Hess, H. Porter, J. B. Jensen, M. A. Condron, D. B. Teplow, J. Sears, M. Maranta, M. Hunter, B. Weber and D. Yaver, "Coronamycins, Peptide Antibiotics Produced by a Verticillate Streptomyces sp. (MSU-2110) Endophytic on Monstera sp.," Microbiology, Vol. 150, No. 4, 2004, pp. 785793. doi:10.1099/mic.0.26645-0

[6] T. Taechowisan, C. Lu, Y. Shen and S. Lumyong, "4-Arylcoumarins from Endophytic Streptomyces aureofaciens CMUAc130 and Their Antifungal Activity," Annals of Microbiology, Vol. 55, No. 1, 2005, pp. 63-66.

[7] T. Taechowisan, C. Lu, Y. Shen and S. Lumyong, "AntiInflammatory Effects of 4-Arylcoumarins in LPS-Induced Murine Macrophage RAW 264.7 Cells," Pharmaceutical Biology, Vol. 44, No. 8, 2006, pp. 576-580. doi:10.1080/13880200600896694

[8] M. Rinetti, G. Ugolotti, B. Calbiani, L. Colombi-Zinelli, M. Cisternino and N. Papa, "Antiinflammatory Drugs and Gastric Emptying. A Comparison between Acetylsalicyclic Acid and Carprofen," Arzneimittelforschung, Vol. 32, No. 12, 1982, pp. 1561-1563.

[9] F. Rubio, S. Seawall, R. Pocelinko, B. DeBarbieri, W. Benz, L. Berger, L. Morgan, J. Pao, T. H. Williams and B. Koechlin, "Metabolism of Carprofen, a Nonsteroid AntiInflammatory Agent, in Rats, Dogs, and Humans," Journal of Pharmaceutical Sciences, Vol. 69, No. 11, 1980, pp. 1245-1253. doi:10.1002/jps.2600691104

[10] T. Taechowisan, J. F. Peberdy and S. Lumyong, "Isolation of Endophytic Actinomycetes from Selected Plants and Their Antifungal Activity," World Journal of Microbiology and Biotechnology, Vol. 19, No. 4, 2003, pp. 381385. doi:10.1023/A:1023901107182

[11] T. Taechowisan and S. Lumyong, "Activity of Endophytics Actinomycetes From Roots of Zingiber officinale and Alpinia galanga against Phytopathogenic Fungi," Annals of Microbiology, Vol. 53, No. 3, 2003, pp. 291-298.

[12] D. P. Chakraborty, K. C. Das and S. P. Basak, "New Synthesis of Isomeric Methylcarbazoles," Journal of the Indian Chemical Society, Vol. 45, No. 1, 1968, pp. 84-86.

[13] H. Furukawa, T. S. Wu, T. Ohta and C. S. Kuoh, "Chemical Constituents of Murraya euchrestifolia HAYATA. Structures of Novel Carbazolequinones and other New Carbazole Alkaloids," Chemical and Pharmaceutical Bulletin, Vol. 33, No. 10, 1985, pp. 4132-4138.

doi:10.1248/cpb.33.4132
[14] M. Chakrabarty and A. Batabyal, "Indolisation of Cyclohexanone Phenylhydrazones Using Phosphorous Trichloride," Indian Journal of Chemistry, Vol. 31B, No. 1, 1992, pp. 199-201.

[15] D. P. Chakraborty, B. K. Barman and P. K. Bose, "On the Constitution of Murrayanine, a Carbazole Derivative Isolated from Murraya koengii Spreng," Tetrahedron, Vol. 21, No.1, No. 2, 1965, pp. 681-685.

[16] M. Fiebig, J. M. Pezzuto, D. D. Soejarto and A. D. Kinghorn, "Koenoline, a Further Cytotoxic Carbazole Alkaloid from Murraya koengii," Phytochemistry, Vol. 24, No. 12, 1985, pp. 3041-3043. doi:10.1016/0031-9422(85)80052-2

[17] J. Reisch, O. Goj, A. Wickramasinghe, H. M. T. Bandara Herath and G. Henkel, "Carbazole Alkaloids from Seeds of Murraya koengii," Phytochemistry, Vol. 31, No. 8, 1992, pp. 2877-2879. doi:10.1016/0031-9422(92)83651-E

[18] C. Ito, Y. Thoyama, M. Omura, I. Kajira and H. Furukawa, "Alkaloidal Constituents of Murraya koengii. Isolation and Structural Elucidation of Novel Binary Carbazolequinones and Carbazole Alkaloids," Chemical and Pharmaceutical Bulletin, Vol. 41, No. 12, 1993, pp. 2096 2100. doi:10.1248/cpb.41.2096

[19] M. Chakrabarty, A. C. Nath, S. Khasnobis, M. Chakrabarty, Y. Konda, Y. Harigaya and K. Komiyama, "Carbazole Alkaloids from Murraya koengii," Phytochemistry, Vol. 46, No. 4, 1997, pp. 751-755. doi:10.1016/S0031-9422(97)00345-2

[20] R. S. Ramsewak, M. G. Nair, G. M. Strasburg, D. L. DeWitt and J. L. Nitiss, "Biologically Active Carbazole Alkaloids from Murraya koenigii," Journal of Agricultural and Food Chemistry, Vol. 47, No. 2, 1999, pp. 444-447. doi:10.1021/jf9805808

[21] N. M. Cuong, T. Q. Hung, T. V. Sung and W. C. Taylor, "A New Dimeric Carbazole Alkaloid from Glycosmis stenocarpa Roots," Chemical and Pharmaceutical Bulletin, Vol. 52, No. 10, 2004, pp. 1175-1178. doi:10.1248/cpb.52.1175

[22] S. V. Tembhurne and D. M. Sakarkar, "Protective Effect of Murraya koenigii (L) Leaves Extract in Streptozotocin Induced Diabetics Rats Involving Possible Antioxidant Mechanism," Journal of Medicinal Plants Research, Vol. 4, No. 22, 2010, pp. 2418-2423.

[23] S. Pandey, S. P. Sah, M. L. Sah and D. Mishra, "An Antioxidant Potential of Hydromethanolic Extract of Urtica parviflora Roxb," Journal of Basic Clinical Pharmacy, Vol. 1, No. 3, 2010, pp. 191-195.

[24] M. Rawat and W. D. Wulff, "Total Synthesis of Carbazoquinocin C: Application of the O-Benzannulation of Fischer Carbene Complexes to Carbazole-3,4-quinone Alkaloids," Organic Letters, Vol. 6, No. 3, 2004, pp. 329-332. doi:10.1021/o10360445

[25] S. Sathaye, Y. Bagul, S. Gupta, H. Kaur and R. Redkar, "Hepatoprotective Effects of Aqueous Leaf Extract and Crude Isolates of Murraya koenigii against in Vitro Ethanol-Induced Hepatotoxicity Model," Experimental and Toxicologic Pathology, Vol. 63, No. 6, 2011, pp. 587-591. doi:10.1016/j.etp.2010.04.012

[26] K. Ahmad, N. F. Thomas, A. H. Hadi, M. R. Mukhtar, K. Mohamad, M. A. Nafiah, K. Takeya, H. Morita, M. Litau- 
don, H. Arai and K. Awang, "Oppositinines A and B: New Vasorelaxant Beta-Carboline Alkaloids from Neisosperma oppositifolia," Chemical and Pharmaceutical Bulletin, Vol. 58, No. 8, 2010, pp. 1085-1087. doi:10.1248/cpb.58.1085

[27] P. Muthumani, S. Venkatraman, K. V. Ramseshu, R. Meera, P. Devi and B. Kameswari, "Pharmacological Studies of Anticancer, Anti-Inflammatory Activities of Murraya koenigii (Linn) Spreng in Experimental Animals," Journal of Pharmaceutical Science \& Research, Vol. 1, No. 3, 2009, pp. 137-141.

[28] S. Mandal, A. Nayak, M. Kar, S. K. Banerjee, A. Das, S. N. Upadhyay, R. K. Singh, A. Banerji and J. Banerji, "Antidiarrhoeal Activity of Carbazole Alkaloids from Murraya koenigii Spreng (Rutaceae) Seeds," Fitoterapia, Vol. 81 , No. 1, 2010, pp. 72-74. doi:10.1016/j.fitote.2009.08.016

[29] S. K. Prasad, A. Kulshreshtha and T. N. Qureshi, "Antidiabetic Activity of Some Herbal Plants in Streptozotocin Induced Diabetic Albino Rats," Pakistan Journal of Nutrition, Vol. 8, No. 5, 2009, pp. 551-557. doi:10.3923/pjn.2009.551.557

[30] S. Parmar, A. Gangwal and N. Shethh, "Evaluation of Anti-Asthmatic Activity of a Polyherbal Formation Containing Four Plant Extracts," Journal of Current Pharmaceutical Research, Vol. 2, No. 1, 2010, pp. 40-44.

[31] G. Bringmann, A. Ledermann, J. Holenz, M. T. Kao, U. Busse, H. G. Wu and G. François, "Antiplasmodial Activity of Mono- and Dimeric Carbazoles," Planta Medica, Vol. 64, No. 1, 1998, pp. 54-57. doi:10.1055/s-2006-957366

[32] T. K. Khuntia and D. S. Panda, "Evaluation of Antibacterial, Antifungal and Anthelmintic Activity of Murraya koenigii Spreng," Pharma Science Monitor, Vol. 2, No. 2, 2011, pp. 105-110.
[33] C. B. Cui, S. Y. Yan, B. Cai and X. S. Yao, "Carbazole Alkaloids as New Cell Cycle Inhibitor and Apoptosis Inducers from Clausena dunniana Levl," Journal of Asian Natural Products Research, Vol. 4, No. 4, 2002, pp. 233241. doi:10.1080/1028602021000049041

[34] C. Ma, R. J. Case, Y. Wang, H. J. Zhang, G. T. Tan, N. Van Hung, N. M. Cuong, S .G. Franzblau, D. D. Soejarto, H. H. Fong and G. F. Pauli, "Anti-Tuberculosis Constituents from the Stem Bark of Micromelum hirsutum," Planta Medica, Vol. 71, No. 3, 2005, pp. 261-267. doi:10.1055/s-2005-837826

[35] M. Gilliet and R. Lande, "Antimicrobial Peptides and SelfDNA in Autoimmune Skin Inflammation," Current Opinion in Immunology, Vol. 20, No. 4, 2008, pp. 401-407. doi:10.1016/i.coi.2008.06.008

[36] O. Takeuchi and S. Akira, "Toll-Like Receptors; Their Physiological Role and Signal Transduction System," International Immunopharmacology, Vol. 1, No. 4, 2001, pp. 625-635.

[37] L. C. Chang, L. T. Tsao, C. S. Chang, C. J. Chen, L. J. Huang, S. C. Kuo, R. H. Lin and J. P. Wang, "Inhibition of Nitric Oxide Production by the Carbazole Compound LCY-2-CHO via Blockade of Activator Protein-1 and CCAAT/Enhancer-Binding Protein Activation in Microglia," Biochemical Pharmacology, Vol. 76, No. 4, 2008, pp. 507-519. doi:10.1016/j.bcp.2008.06.002

[38] F. M. Ho, C. C. Lai, L. J. Huang, T. C. Kuo, C. M. Chao and W. W. Lin, "The Anti-Inflammatory Carbazole, LCY2-CHO, Inhibits Lipopolysaccharide-Induced Inflammatory Mediator Expression through Inhibition of the p38 Mitogen-Activated Protein Kinase Signaling Pathway in Macrophages," British Journal of Pharmacology, Vol. 141, No. 6, 2004, pp. 1037-1047. doi:10.1038/sj.bjp. 0705700 